\title{
Probable impact of age and hypoxia on proliferation and microRNA expression profile of bone marrow-derived human mesenchymal stem cells
}

Norlaily Mohd Ali, Lily Boo, Swee Keong Yeap, Huynh Ky, Dilan A Satharasinghe, Woan Charn Liew, Han Kiat Ong, Soon Keng Cheong, Tunku Kamarul

Decline in the therapeutic potential of bone marrow-derived mesenchymal stem cells (MSC) is often seen with older donors as compared to young. Although hypoxia is known as an approach to improve the therapeutic potential of MSC in term of cell proliferation and differentiation capacity, its effects on MSC from aged donors have not been well studied. To evaluate the influence of hypoxia on different age groups, MSC from young ( $<30$ years) and aged (>60 years) donors were expanded under hypoxic ( $5 \%$ O2) and normal $(20 \% 02)$ culture conditions. MSC from old donors exhibited a reduction in proliferation rate and differentiation potential together with the accumulation of senescence features compared to that of young donors. However, MSC cultured under hypoxic condition showed enhanced self-renewing and proliferation capacity in both age groups as compared to normal condition. Bioinformatic analysis of the gene ontology (GO) and KEGG pathway under hypoxic culture condition identified hypoxia-inducible miRNAs that were found to target transcriptional activity leading to enhanced cell proliferation, migration as well as decrease in growth arrest and apoptosis through the activation of multiple signaling pathways. Overall, differentially expressed miRNA provided additional information to describe the biological changes of young and aged MSCs expansion under hypoxic culture condition at the molecular level. Based on our findings, the therapeutic potential hierarchy of MSC according to donor's age group and culture conditions can be categorized in the following order: young (hypoxia) > young (normoxia) > old aged (hypoxia) > old aged (normoxia). 
1 Probable impact of age and hypoxia on proliferation and microRNA expression profile of

2

3

4 Norlaily Mohd Ali ${ }^{1}$, Lily Boo ${ }^{1}$, Swee Keong Yeap ${ }^{2}$, Huynh Ky ${ }^{3,4}$, Dilan Amila Satharasinghe ${ }^{2,5}$, 5

24 ABSTRACT

\section{bone marrow-derived human mesenchymal stem cells}

${ }^{1}$ Faculty of Medicine and Health Sciences, Universiti Tunku Abdul Rahman, 43000 Cheras, Malaysia

${ }^{2}$ Institute of Bioscience, Universiti Putra Malaysia, 43400 Serdang, Malaysia

${ }^{3}$ Faculty of Biotechnology and Biomolecular Sciences, Universiti Putra Malaysia, 43400

Serdang, Malaysia

${ }^{4}$ Department of Agriculture Genetics and Breeding, College of Agriculture and Applied Biology, Cantho University, 84071, Vietnam

${ }^{5}$ Faculty of Veterinary Medicine and Animal Science, University of Peradeniya, 20400, Sri

Lanka

${ }^{6}$ Cryocord Sdn Bhd, Persiaran Cyberpoint Selatan, 63000 Cyberjaya, Malaysia

${ }^{7}$ Tissue Engineering Group (TEG), National Orthopaedic Center of Excellence for Research and Learning (NOCERAL), Faculty of Medicine, Universiti Malaya, 50603 Kuala Lumpur, Malaysia E-mail address: onghk@utar.edu.my

Phone: +603-90194722 
25 Decline in the therapeutic potential of bone marrow-derived mesenchymal stem cells (MSC) is

26 often seen with older donors as compared to young. Although hypoxia is known as an approach

27 to improve the therapeutic potential of MSC in term of cell proliferation and differentiation

28 capacity, its effects on MSC from aged donors have not been well studied. To evaluate the 29 influence of hypoxia on different age groups, MSC from young ( $<30$ years) and aged ( $>60$ years)

30 donors were expanded under hypoxic $\left(5 \% \mathrm{O}_{2}\right)$ and normal $\left(20 \% \mathrm{O}_{2}\right)$ culture conditions. MSC

31 from old donors exhibited a reduction in proliferation rate and differentiation potential together

32 with the accumulation of senescence features compared to that of young donors. However, MSC

33 cultured under hypoxic condition showed enhanced self-renewing and proliferation capacity in

34 both age groups as compared to normal condition. Bioinformatic analysis of the gene ontology

35 (GO) and KEGG pathway under hypoxic culture condition identified hypoxia-inducible miRNAs

36 that were found to target transcriptional activity leading to enhanced cell proliferation, migration

37 as well as decrease in growth arrest and apoptosis through the activation of multiple signaling

38 pathways. Overall, differentially expressed miRNA provided additional information to describe

39 the biological changes of young and aged MSCs expansion under hypoxic culture condition at

40 the molecular level. Based on our findings, the therapeutic potential hierarchy of MSC according

41 to donor's age group and culture conditions can be categorized in the following order: young

42 (hypoxia) $>$ young (normoxia) $>$ old aged (hypoxia) $>$ old aged (normoxia).

INTRODUCTION

Mesenchymal stem cells derived from bone marrow (BM-MSCs) are adult multipotent

47 stem cells with the self-renewing capacity and the ability to differentiate into cells of various 
48 connective tissue lineages. They are regarded as a promising and potential alternative source in

49 the repair of many cells and tissues due to its multilineage differentiation capability into not only

50 mesoderm but also ectodermic and endodermic lineages such as osteoblasts, chondrocytes,

51 adipocytes, neurocytes and myoblasts (Wei et al. 2013; Zhou et al. 2008). MSCs are clinically

52 used in engraftment of post-transplantation or as gene therapy vehicles in osteogenesis

53 imperfecta because of their immunosuppressive capacity and are widely used in the treatment of

54 cardiac disorder, musculoskeletal and cancer (Baxter et al. 2004; Mognetti et al. 2013;

55 Mohyeldin et al. 2010; Oliveira et al. 2012). Outstanding features of MSC are that it can be

56 easily obtained from various sources of adult tissue (adipose and bone-marrow) and postnatal

57 tissues (Wharton-jelly and umbilical cord) and can be expanded in vitro (Oliveira et al. 2012;

58 Samsonraj et al. 2013).

59 The challenge for MSC-therapy is that it requires high yield and good quality of stem

60 cells. In order to get sufficient yield, stem cells need to be expanded under prolonged passage,

61 which can lead to deterioration of its self-renewal and differentiation capacity. Prolonged

62 passage has been reported to be directly linked with the shortening of telomere length that leads

63 to decrease in cell proliferation and increase of senescence (Samsonraj et al. 2013). Age is

64 another factor that is associated with progressive loss of cell proliferation resulting in cellular

65 senescence. Biological markers of cellular senescence were highly expressed in MSC from aged

66 donors along with oxidative damage indicators (Reactive oxygen species (ROS) and nitric oxide)

67 (Stenderup et al. 2003; Stolzing et al. 2008). The acceleration of senescence was related with the

68 decrease of cell proliferation and their life span as well as contributing to the accumulation of

69 DNA damage leading to stem cell exhaustion (Rube et al. 2011). These marked the compromised

70 quality of MSCs with age as well as prolonged passage under normal condition. Despite that, in 
71 the case of autologous MSC transplantation for severe autoimmune diseases and old age related

72 diseases in aged patients, the use of MSC of aged donor is still highly in demand (Wang et al.

73 2013; Wei et al. 2013).

74 Alternatively, low oxygen content $\left(5 \% \mathrm{O}_{2}\right)$, referred as hypoxia, is regarded as a

75 characteristic feature of their microenvironment in vivo that provides microenvironmental

76 stresses to stem cells, allowing them to escape senescence pathways resulting in an increased

77 proliferation rate (Efimenko et al. 2011). Hypoxia is known to stimulate pro-angiogenic effects

78 in stem cells while maintaining the telomere length (Efimenko et al. 2011; Oliveira et al. 2012).

79 Most of our knowledge concerning MSC's differentiation and proliferation potential reduction

80 by age had been obtained from cell cultured under normal oxygen as well as hypoxia conditions.

81 Although the hypoxic condition has been demonstrated as a mode to improve the therapeutic

82 potential of MSC (Cicione et al. 2013; Guan et al. 2012; Peterson et al. 2011; Rosova et al. 2008),

83 little is known about its effect on a specific age group, especially in the involvement and the

84 interplay of miRNAs in the proliferation and renewal properties. As an important class of

85 regulatory noncoding RNAs, miRNAs have been shown to play important roles in the committed

86 differentiation and self-renewal of embryonic stem cells and adult stem cells (Huang et al. 2010).

87 Interestingly, the miRNA expression patterns in MSC when subjected to various factors and

88 culture conditions such as hypoxia and serum deprivation differ considerably (Nie et al. 2011).

89 By preventing the translation of mRNAs, miRNAs are predicted to regulate almost all cell's

90 biological processes, ranging from cell renewal, differentiation, migration, tumorigenesis to cell

91 death, aging and senescence (Di Leva \& Croce 2013; Nie et al. 2011; Tome et al. 2011). 
93 profiles of BM-MSCs expanded under hypoxic culture and discovered several miRNAs that may 94 potentially act as key regulators.

\section{MATERIALS AND METHODS}

\section{Hypoxic culture of human BM-derived MSCs}

The primary BM-MSC collection was obtained from Cryo Cord Sdn Bhd and the research approved by the UTAR Scientific and Ethical Review Committee (U/SERC/14/2012), in compliance with international guidelines regarding the use of primary bone marrow stem cell for research and signed consent were obtained prior to study. BM-derived MSC was prepared as described previously (Efimenko et al. 2011). Six subjects $(\mathrm{F} / \mathrm{M}=4 / 2 /$; Age $=19-80$ years old) are with no metabolic disease, inherited diseases and other diseases which may affect the current study. MSCs from young ( $\leq 30$ years old) and aged ( $\geq 60$ years old) donors were ( $\mathrm{n}=3$ /group) maintained in Dulbecco's modified Eagle's medium (DMEM, Sigma, USA) supplemented with $10 \%$ fetal bovine serum (GIBCO, USA) at $37^{\circ} \mathrm{C}$, in $5 \% \mathrm{CO}_{2}$ and $20 \% \mathrm{O}_{2}$. Hypoxic (Hx) condition was attained by culturing cells in a gas mixture composed of $94 \% \mathrm{~N}_{2}, 5 \% \mathrm{CO}_{2}$, and $5 \%$ assay. The population doubling was determined using the formula $x=\log 2(\mathrm{~N} 2) /(\mathrm{N} 1) / \log 2$,

110 where N2 is the number of harvested cells, and N1 is the number of seeded cells. To calculate the

111 CPD, population doubling in each passage was determined and compared with the population

112 doubling of earlier passages (Stolzing et al. 2008).

\section{MSC characterizations}




\section{Immunophenotyping of MSCs}

116 Identification of MSCs was performed using CD90, CD44, CD105 and CD19 MSC surface

117 markers from Flow Cellect kit (Merck, USA). Cells were incubated with $18 \mu \mathrm{L}$ of antibody

118 working cocktail solution (Anti-human CD105-conjugated with FITC, anti-human CD90-

119 conjugated with PE, anti-human CD44-conjugated with Alexa fluor 647, anti-human CD19-

120 conjugated with PECy5) for 30 minutes in the dark at $4{ }^{\circ} \mathrm{C}$ and acquired using a BD FACS Canto

121 TM II Flow Cytometer (Becton Dickinson, USA).

122

123 Multipotent differentiation

124 The multipotency of MSCs were evaluated using adipogenic and osteogenic assays (Pandey et al.

125 2011). Both MSC groups expanded under normoxic and hypoxic conditions were cultured in 126 low-glucose DMEM containing 10\% fetal bovine serum, antibiotics, $100 \mathrm{U} / \mathrm{ml}$ penicillin and 100

$127 \mu \mathrm{g} / \mathrm{ml}$ streptomycin and $2 \mathrm{mM}$ L-glutamine until $90 \%$ confluent. For in vitro differentiation into 128 osteoblasts, cells were induced with osteogenic induction medium (OIM), composed of DMEM

129 supplemented with $10 \% \mathrm{FBS}, 50 \mu \mathrm{g} / \mathrm{mL}$ ascorbate- 2 phosphate, $10^{8} \mathrm{M}$ dexamethasone, and $13010 \mathrm{mM} \beta$-glycerophosphate. For in vitro differentiation into adipocytes, cells were induced with 131 adipogenic induction medium (AIM), composed of DMEM supplemented with 10\% FBS, 50 $132 \mu \mathrm{g} / \mathrm{mL}$ ascorbate-2 phosphate, $10^{7} \mathrm{M}$ dexamethasone, $50 \mu \mathrm{M}$ indomethacin, $0.45 \mathrm{mM}$ 3-isobutyl133 1-methyl- xanthine (IBMX) and $10 \mu \mathrm{g} / \mathrm{mL}$ insulin. Change of medium was performed every 3 134 days until 21 days when the matrix mineralization and lipid droplets were fully formed. 135

\section{$136 \boldsymbol{\beta}$-galactosidase staining}


137 Confluent cells were fixed with $2 \%$ formaldehyde for 5 minutes and incubated with senescence-

138 associated $\beta$-Gal (SA- $\beta$-Gal) chromogenic substrate solution (Cell Signaling Technology, USA).

139 The mean percentage of cells expressing $\beta$-galactosidase was quantified using ImageJ with an

140 average of 200 cells.

141

142 Next Generation Sequencing (NGS) of miRNA

143 Total RNAs including small RNAs were isolated from cells at passage 15 using a miRNeasy kit

144 (Qiagen, USA). The next generation sequencing (NGS) library was prepared using TruSeq small

145 RNA sample prep kit (Illumina, USA). Briefly, 3' and 5' RNAs adapters were ligated to small

146 RNAs molecules, reverse-transcribed and PCR amplified. Prior to amplification, indices for

147 sample multiplexing were incorporated. Samples in the same multiplex group were pooled and

148 run on a $6 \%$ SDS-PAGE and validated using an Agilent Technologies Bioanalyzer high

149 sensitivity DNA chip. Data were analyzed using CLC Genomic Workbench 7.0 and sequence

150 with length less than 17 or more than 27 were removed. miRNA sequences were aligned to

151 human genome (Homo sapiens GRCh 37.57) and known miRNA database (miRBase-19) of both

152 mature and miRNA precursors (Noren Hooten et al. 2013).

153

154 Pathway Analysis

155 Target genes were identified using a target prediction program miRDB. The identified genes

156 were further analyzed using the web-based DAVID Bioinformatic Resource functional

157 annotation tool (http://david.abcc.ncifcrf.gov/) for pathway analysis to identify the gene ontology

158 (GO) and significantly enriched pathways using the Kyoto Encyclopedia of Genes and Genomes

159 (KEGG). 
161 MicroRNAs quantification by Real-time PCR analysis

162 Five miRNAs were selected to validate NGS data. cDNA synthesis and real-time qPCR were

163 performed with miRCURY LNA Universal RT microRNA PCR (Exiqon, Denmark). In brief,

164 RNAs were tailed with a poly (A) sequence at their 3'end and reverse-transcribed into cDNA

165 using a universal poly (T) primer with a 3'end degenerate anchor and a 5'end universal tag. The

166 cDNA products were quantified using SYBR green based real time PCR and locked nucleic acid

167 (LNA) enhanced miRNA specific primers. The qPCR analysis was run on a CFX96 ${ }^{\mathrm{TM}}$ touch

168 thermocycler (Biorad) (Jensen et al. 2011). Normalization was done using the average value of

169 miR-200a, miR-122-5p and miR-16 evaluated using geNorm algorithms. Primer sequences for

170 qPCR are listed in Table 1.

171

172 Statistical analysis

173 Data are expressed as means \pm standard deviations. Statistical analyses were performed using 174 one-way analysis of variance (ANOVA), FDR correction and Duncan's post hoc test. The results 175 were taken to be significant at a probability level of $p$-values $<0.05$.

176

177 RESULTS

178 Comparison of BM-MSC of young and aged donors under hypoxic and prolonged passage conditions

180 MSC surface marker expressions showed that CD105, CD90 and CD44 were strongly expressed

181 in young MSC whereas in aged MSC, the markers were present but the expression level was

182 slightly lower. Meanwhile, the expression of CD19 surface marker was not detectable on either

183 young or aged MSC (Fig. 1A) confirming that both groups exhibited phenotype common to 
184 MSC. In normal oxygen condition, the proliferation rate of MSC remained relatively high during

185 low passage. As the number of passage increased, the proliferation rate of aged MSC declined

186 significantly. Meanwhile, MSCs subjected to hypoxic treatment exhibited relatively higher

187 proliferation rate in both groups. Overall, aged MSC had significantly lower cumulative

188 population doubling (CPD) compared to young MSC (Fig. 1B), which further showed a

189 comparatively reduced proliferation rate, resulting in growth arrest or early senescence. This was

190 further supported based on morphological assessment where young MSC displayed fibroblast-

191 like morphology with a long-spindle shape whereas substantial alteration of morphology such as

192 loss of their characteristic spindle-shaped morphology and increase in cytoplasmic volume and

193 size (spread-out and polygonal shape) in aged MSC (Fig. 1C). The positive staining of Alizarin

194 Red and Oil Red O confirmed the multilineage differentiation of hypoxic-treated MSCs into

195 osteocytes and adipocytes (Fig. 1D). A decline in the formation of calcium deposition and the

196 number of cells with lipid droplets in hypoxic conditions of MSC from aged donors compared to

197 the young donors was noticed indicating the reduction in their differentiation ability.

198 Differentiation ability was further confirmed with differentiation markers (aP2, adiponectin,

199 RUNX2 and osteopontin) using RT-PCR (Fig.1E). Subsequently, percentage of MSC positive

200 for SA- $\beta$-gal increased tremendously with age as a substantial expression of blue color SA- $\beta$-gal

201 positive cells were detected in aged MSC compared to young (Fig. 1F). Furthermore, cells

202 expanded under hypoxic condition had a lower senescence expression relative to the cells 203 expanded under normal condition. 204

205 miRNAs expression profiles in hypoxia-treated MSC 
206 To screen miRNAs that might be involved in hypoxia implicated cell fate commitment leading to

207 increase of cellular proliferation and differentiation potential, next gene sequencing using

208 Illumina platform was used to compare miRNA expression profiles of MSC between young and

209 aged donors (Fig. 2). On average, 3.2 million effective reads were obtained from young MSC

210 and 4.0 million effective reads from aged MSC with a quality score $(>Q 30)$ of $93.3 \%$. The

211 average length of the detected sequences was 21.6 nucleotides after the removal of the $5^{\prime}$ and $3^{\prime}$

212 adapter sequences. An average of $46.8 \%$ and $38.6 \%$ small RNAs were obtained from young and

213 aged MSC respectively using miRBase-19 database. Meanwhile, $53.2 \%$ and $61.4 \%$ small RNAs

214 were obtained from young and aged MSC respectively using Homo sapiens GRCh 37.57 library.

215 Approximately, 27-34\% of the small RNAs matched with the known human miRNAs, and the

216 remaining unmatched sequences $(65-72 \%)$ were classified as novel miRNAs. All the data has

217 been deposited in the geo@ncbi.nlm.nih.gov database (GEO accession number: GSE67630). The

218 distribution of miRNAs that are commonly upregulated and downregulated in young and old

219 MSC donors were illustrated in Venn-diagram (Figure 3 A, B). The overlap miRNAs from each

220 group might contribute to similar phenotype observed in the study. Relative distances between

221 the miRNA profiles of different age groups and hypoxic treatment populations were shown in

222 principal component analyses (PCA) plot (Figure 3C). A total of nine and two miRNAs with fold

223 change $>2$ were up-regulated in young and aged MSC respectively. Meanwhile, four and 31

224 miRNAs with fold change $>2$ were down-regulated in young and aged MSC respectively (Table 225 2).

226

227 Target genes, gene ontology (GO) and KEGG pathways of differentially expressed miRNAs 
228 To assess the possible biological impact of the differentially expressed miRNAs in MSC, the

229 predicted target genes of miRNAs (fold change $>2, p>0.05$ ) were analyzed. A total of 2,118 and

2303,617 potential targets were identified through this process for differentially expressed miRNAs

231 in young and aged MSCs respectively. In young MSC, the putative target genes of known

232 miRNAs appeared to be involved in a broad range of GO analysis (biological processes) with

233 most of them related to transcriptional categories such as regulation of transcription and

234 inflammatory response to stress (GO:0043619, GO:0043618) (Table 4A), whereas in aged MSC,

235 negative regulation of epithelial to mesenchymal transition (GO:0010719) and differentiation

236 (GO:0010771) were among the top 10 most prominent terms (Table 4B).

237

238 The signaling pathways that were found to be involved in KEGG analysis of MSC from young 239 donors included ErbB signaling, melanogenesis, Wnt, MAPK and GnRH signaling pathways

240 (Table 5). Meanwhile, cell cycle, Wnt, p53 and calcium signaling pathway were the most

241 enriched pathways seen in MSC from aged donors. Cell cycle and p53-signaling pathways are

242 involved in replicative senescence leading to permanent growth arrest. Moreover, pathways

243 involved in various signal transduction and cell-cell interactions such as Wnt and MAPK

244 signaling pathways and others were significantly enriched in both young and aged MSC.

\section{Quantitative RT-PCR validation of selected microRNA}

247 To validate miRNA expression changes in MSC after hypoxic treatment, we performed the RT248 qPCR of the five highly dysregulated miRNAs (miR-21, miR-34b, miR-210, miR-19b, miR-33a).

249 The miRNAs were selected for validation based on statistical significance $(\mathrm{P}<0.05)$ and their key 250 role in biological or signaling pathways altered in hypoxic treatment with respect to control 
251 (normal) culture condition. As illustrated in Fig.4 and Supplementary Table 4, the NGS data

252 correlated well with the RT-qPCR results, indicating the reliability of sequencing based 253 expression analysis.

\section{DISCUSSION \& CONCLUSIONS}

256 The latest profiling platform, NGS was used to generate miRNA expression profiles and further 257 elaborate the relationship of hypoxia-inducible miRNA in young and aged MSC. The 258 introduction of high throughput sequencing approaches has provided opportunities to generate 259 inclusive sequencing data for the identification and quantification of reproducible known and 260 novel miRNAs compared to previous approaches such as qPCR and microarray. In normal 261 culture condition of prolonged passage, aged MSC displayed a great reduction in viability 262 causing the cells to undergo morphological transformation, senescence and detachment leading 263 to cell death. This is in contrast with young MSC, which retained their MSC characteristics. This 264 finding is showing that MSC isolated from old donors tend to exhibit slower progress on their 265 proliferation, expansion and differential capacity relative to young MSC, similar to a previous 266 study reported by other researchers (Choudhery et al. 2014). Meanwhile, MSC cultured under

267 hypoxic condition showed enhanced self-renewal and proliferation capacity in both age groups 268 compared to normal condition. Nevertheless, young MSC performed better than the aged MSC. Research on the roles of hypoxia-related miRNAs in age-related MSC will have great

270 significance on therapeutic applications of MSC. We therefore hypothesize that these 2 groups of 271 MSCs (young and old age) have distinct etiologies and could present potentially different 272 pathways that might involve and converge in a common biological processes particularly in the 273 proliferation and differentiation processes. Sequencing results revealed differential expression of 
274 several hypoxia-inducible miRNAs in young MSC (Table 2). The up-regulation of miR-210,

275 miR-21 and miR-155 as well as down-regulation of let-7i and miR-33a, were among those that

276 were predicted to target mRNAs associated with transcriptional activity leading to enhanced cell

277 proliferation, survival and migration as well as a decrease in growth arrest and apoptosis

278 (Bruning et al. 2011; Clark et al. 2014). Meanwhile, miR-627 (negative regulator of

279 proliferation) and miR-193a (anti-apoptotic regulator) were significantly down-regulated in aged

280 MSC. Moreover, miR-193a was previously found to inhibit ErbB protein translation, which

281 subsequently inhibited cell proliferation and promoted apoptosis in tumor. ErbB signal is

282 important for stem cells development and maintenance (Liang et al. 2015). Our finding

283 demonstrated the involvement of hypoxia in inhibiting miR-627 and miR-193a expression in

284 aged MSC and consequently contributed to increase in proliferation activity. As a whole, this

285 study indicates the possible link of hypoxia-inducible miRNAs in regulating survival and self-

286 renewal, thereby improving the proliferation activity of young and aged MSCs relative to normal 287 oxygen culture condition.

288 Furthermore, it was shown that the age of donor's MSC played a role in the capacity to 289 differentiate into certain lineages. The reduction of adipocyte and osteocyte differentiation was 290 clearly seen in prolonged passage of aged MSC. Previous research reported that shortening of 291 telomere length might be the cause of reduction in differentiation and self-renewal capacity 292 (Zhou et al. 2008). The miRNAs identified in this study that were up-regulated by hypoxia (miR293 210, miR-29b) in young MSC and down-regulated (miR-196a, miR-148b) in aged MSC were 294 shown to be involved in promoting osteocytes lineage differentiation. Similarly, miRNAs that 295 were involved in adipocyte differentiation (miR-21) was found to be up-regulated in young and 296 down-regulated in aged MSC. A set of highly down-regulated miRNAs in aged MSC, notably 
297 miR-29a and miR-29b (regulated chondrogenic differentiation, cartilage formation and neuronal 298 differentiation) and miR-561 (post-transcriptional regulation of mRNAs) were reported to be

299 associated with human embryonic and other stem cells (Duan et al. 2014; Guerit et al. 2014).

300 Induction and inhibition of these hypoxia-inducible miRNAs may explain their role in the

301 differentiation capacity of MSC. Based on the previous findings and our results, it is highly

302 probable that hypoxic conditioning may promote MSC survival via regulation of various 303 miRNAs.

304 Bioinformatic analysis and target prediction have been used as the main methods to 305 explore the function of miRNAs. The genes possibly regulated by hypoxia-inducible miRNAs 306 are involved in both tumorigenesis and stem cell maintenance such as cell survival, 307 differentiation, angiogenesis, apoptosis, cell cycle regulation, mitochondrial metabolism as well 308 as DNA damage repair (Huang et al. 2010; Kondo et al. 2001; Tsai et al. 2011). MiR-210 and 309 miR-21 were reported to regulate cell proliferation by targeting fibroblast growth factor receptor310 like 1 (FGFRL1) (Table 3) (Huang et al. 2010; Tsuchiya et al. 2011). MiR-155 was found to be 311 up-regulated in young MSC and inhibition of miR-155 in senescence cells was reported to cause

312 an elevated level of a protein involved in the TP53 growth arrest pathway (TP53INP1) (Table

313 5B) (Faraonio et al. 2012). Young MSC cultured under hypoxia which showed an up-regulation

314 of miR-155 was able to maintain its proliferative activity and has yet to reach the growth arrest

315 and senescence stage. The results indicated that hypoxia-inducible miRNAs are predicted to 316 target mRNAs and transcriptional activity leading to enhanced cell proliferation and migration as 317 well as a decrease in growth arrest and apoptosis which may serve as a clinical marker for the 318 proliferation and expansion in MSC. 
A previous finding reported that adipogenic and osteogenic differentiation capacity of

320

\section{1}

322

323

324

MSC diminishes with age ( $\mathrm{Yu}$ et al. 2011). MiR-210 and miR-29a have been identified as positive regulators of osteocyte differentiation by inhibiting the TGF-beta/activin signaling pathway through the inhibition of the target gene AcvRlb in MSC (He et al. 2013). In our studies, a similar trend could be observed where miR-210 was predicted to target the putative gene TGF-beta that might be involved in promoting osteogenesis and adipogenesis in young MSC. Meanwhile miR-29a was highly down-regulated in aged MSC in which the differentiation into osteocytes was shown to be inhibited.

Overall, significantly differentially expressed miRNAs in both young and aged MSCs after hypoxic exposure were mostly shown to target putative genes (Table 3) involving multilineage differentiation, proliferation as well as apoptosis (Table 4). Each differentially expressed miRNAs (up-regulated and down-regulated) with hundreds of predicted target putative genes that were linked with multiple GO and KEGG pathways were combined and hypoxiarelated miRNAs were shown and presumed to be the main drivers and regulators of proliferation and differentiation favoring young MSC.

Here we reported the different profiles of hypoxia-inducible miRNA signatures between young and aged MSCs, thereby providing additional information on possible link of miRNAs associated with hypoxic condition that increased the proliferation of both young and aged MSCs. These miRNAs can be further used as molecular markers for screening the quality of MSC. In conclusion, our results showed that both young and aged MSCs cultured under hypoxia performed better than normal condition. In this respect, hypoxia enhanced the self-renewal and multi-potent differentiation potential of BM-MSC especially in aged (compromised) MSC. This study not only provided further understanding on the likely effects of age in inducing biological 
342 changes in MSC, but more importantly the molecular changes critical to the successful

343 application of MSC in regenerative medicine.

344

345

\section{ACKNOWLEDGEMENTS}

346 We would like to thank CryoCord Sdn. Bhd. for providing the bone marrow-derived

347 mesenchymal stem cells.

348

349

350

351

352

353

354

355

356

357

358

359

360

361

362

363

364

365

366

367

368

369

370

371

372

373

374

375

376

377

378

\section{REFERENCES}

Baxter MA, Wynn RF, Jowitt SN, Wraith JE, Fairbairn LJ, and Bellantuono I. 2004. Study of telomere length reveals rapid aging of human marrow stromal cells following in vitro expansion. STEM CELLS 22:675-682.

Bruning U, Cerone L, Neufeld Z, Fitzpatrick SF, Cheong A, Scholz CC, Simpson DA, Leonard MO, Tambuwala MM, Cummins EP, and Taylor CT. 2011. MicroRNA-155 promotes resolution of hypoxia-inducible factor 1alpha activity during prolonged hypoxia. Mol Cell Biol 31:4087-4096.

Choudhery MS, Badowski M, Muise A, Pierce J, and Harris DT. 2014. Donor age negatively impacts adipose tissue-derived mesenchymal stem cell expansion and differentiation. $J$ Transl Med 12:8.

Cicione C, Muinos-Lopez E, Hermida-Gomez T, Fuentes-Boquete I, Diaz-Prado S, and Blanco FJ. 2013. Effects of severe hypoxia on bone marrow mesenchymal stem cells differentiation potential. Stem Cells Int 2013:232896.

Clark EA, Kalomoiris S, Nolta JA, and Fierro FA. 2014. Concise Review: MicroRNA Function in Multipotent Mesenchymal Stromal Cells. STEM CELLS 32:1074-1082.

Di Leva G, and Croce CM. 2013. miRNA profiling of cancer. Curr Opin Genet Dev 23:3-11.

Duan P, Sun S, Li B, Huang C, Xu Y, Han X, Xing Y, and Yan W. 2014. miR-29a modulates neuronal differentiation through targeting REST in mesenchymal stem cells. PLoS One 9:e97684.

Efimenko A, Starostina E, Kalinina N, and Stolzing A. 2011. Angiogenic properties of aged adipose derived mesenchymal stem cells after hypoxic conditioning. Journal of Translational Medicine 9:10.

Faraonio R, Salerno P, Passaro F, Sedia C, Iaccio A, Bellelli R, Nappi TC, Comegna M, Romano S, Salvatore G, Santoro M, and Cimino F. 2012. A set of miRNAs participates in the cellular senescence program in human diploid fibroblasts. Cell Death Differ 19:713-721.

Guan JZ, Guan WP, Maeda T, and Makino N. 2012. Different levels of hypoxia regulate telomere length and telomerase activity. Aging Clin Exp Res 24:213-217. 
379

380

381

382

383

384

385

386

387

388

389

390

391

392

393

394

395

396

397

398

399

400

401

402

403

404

405

406

407

408

409

410

411

412

413

414

415

416

417

418

419

420

421

422

423

424

Guerit D, Brondello JM, Chuchana P, Philipot D, Toupet K, Bony C, Jorgensen C, and Noel D. 2014. FOXO3A regulation by miRNA-29a Controls chondrogenic differentiation of mesenchymal stem cells and cartilage formation. Stem Cells Dev 23:1195-1205.

He X, Zhang W, Liao L, Fu X, Yu Q, and Jin Y. 2013. Identification and characterization of microRNAs by high through-put sequencing in mesenchymal stem cells and bone tissue from mice of age-related osteoporosis. PLoS One 8:e71895.

Huang X, Le QT, and Giaccia AJ. 2010. MiR-210--micromanager of the hypoxia pathway. Trends Mol Med 16:230-237.

Jensen S, Lamy P, Rasmussen M, Ostenfeld M, Dyrskjøt L, Ørntoft T, and Andersen C. 2011. Evaluation of two commercial global miRNA expression profiling platforms for detection of less abundant miRNAs. BMC Genomics 12:1-12.

Kondo A, Safaei R, Mishima M, Niedner H, Lin X, and Howell SB. 2001. Hypoxia-induced enrichment and mutagenesis of cells that have lost DNA mismatch repair. Cancer Research 61:7603-7607.

Liang H, Liu M, Yan X, Zhou Y, Wang W, Wang X, Fu Z, Wang N, Zhang S, and Wang Y. 2015. miR-193a-3p Functions as a Tumor Suppressor in Lung Cancer by Downregulating ERBB4. Journal of Biological Chemistry 290:926-940.

Mognetti B, Montagna GL, Perrelli MG, Pagliaro P, and Penna C. 2013. Bone marrow mesenchymal stem cells increase motility of prostate cancer cells via production of stromal cell - derived factor - $1 \alpha$. Journal of Cellular and Molecular Medicine 17:287292.

Mohyeldin A, Garzon-Muvdi T, and Quinones-Hinojosa A. 2010. Oxygen in stem cell biology: a critical component of the stem cell niche. Cell Stem Cell 7:150-161.

Nie Y, Han BM, Liu XB, Yang JJ, Wang F, Cong XF, and Chen X. 2011. Identification of MicroRNAs involved in hypoxia- and serum deprivation-induced apoptosis in mesenchymal stem cells. Int J Biol Sci 7:762-768.

Noren Hooten N, Fitzpatrick M, Wood WH, 3rd, De S, Ejiogu N, Zhang Y, Mattison JA, Becker $\mathrm{KG}$, Zonderman AB, and Evans MK. 2013. Age-related changes in microRNA levels in serum. Aging (Albany NY) 5:725-740.

Oliveira PH, Boura JS, Abecasis MM, Gimble JM, da Silva CL, and Cabral JMS. 2012. Impact of hypoxia and long-term cultivation on the genomic stability and mitochondrial performance of ex vivo expanded human stem/stromal cells. Stem Cell Research 9:225236.

Pandey AC, Semon JA, Kaushal D, O'Sullivan RP, Glowacki J, Gimble JM, and Bunnell BA. 2011. MicroRNA profiling reveals age-dependent differential expression of nuclear factor kappaB and mitogen-activated protein kinase in adipose and bone marrow-derived human mesenchymal stem cells. Stem Cell Research and Therapy 2:49.

Peterson KM, Aly A, Lerman A, Lerman LO, and Rodriguez-Porcel M. 2011. Improved survival of mesenchymal stromal cell after hypoxia preconditioning: role of oxidative stress. Life Sciences 88:65-73.

Rosova I, Dao M, Capoccia B, Link D, and Nolta JA. 2008. Hypoxic preconditioning results in increased motility and improved therapeutic potential of human mesenchymal stem cells. STEM CELLS 26:2173-2182.

Rube CE, Fricke A, Widmann TA, Furst T, Madry H, Pfreundschuh M, and Rube C. 2011. Accumulation of DNA damage in hematopoietic stem and progenitor cells during human aging. PLoS One 6:e17487. 
425

426

427

428

429

430

431

432

433

434

435

436

437

438

439

440

441

442

443

444

445

446

447

448

449

450

451

452

453

454

455

456

457

458

459

460

461

462

463
Samsonraj RM, Raghunath M, Hui JH, Ling L, Nurcombe V, and Cool SM. 2013. Telomere length analysis of human mesenchymal stem cells by quantitative PCR. Gene 519:348355.

Stenderup K, Justesen J, Clausen C, and Kassem M. 2003. Aging is associated with decreased maximal life span and accelerated senescence of bone marrow stromal cells. Bone 33:919-926.

Stolzing A, Jones E, McGonagle D, and Scutt A. 2008. Age-related changes in human bone marrow-derived mesenchymal stem cells: consequences for cell therapies. Mechanisms of Ageing and Development 129:163-173.

Tome M, Lopez-Romero P, Albo C, Sepulveda JC, Fernandez-Gutierrez B, Dopazo A, Bernad A, and Gonzalez MA. 2011. miR-335 orchestrates cell proliferation, migration and differentiation in human mesenchymal stem cells. Cell Death Differ 18:985-995.

Tsai CC, Chen YJ, Yew TL, Chen LL, Wang JY, Chiu CH, and Hung SC. 2011. Hypoxia inhibits senescence and maintains mesenchymal stem cell properties through downregulation of E2A-p21 by HIF-TWIST. Blood 117:459-469.

Tsuchiya S, Fujiwara T, Sato F, Shimada Y, Tanaka E, Sakai Y, Shimizu K, and Tsujimoto G. 2011. MicroRNA-210 regulates cancer cell proliferation through targeting fibroblast growth factor receptor-like 1 (FGFRL1). J Biol Chem 286:420-428.

Ueyama H, Horibe T, Hinotsu S, Tanaka T, Inoue T, Urushihara H, Kitagawa A, and Kawakami K. 2012. Chromosomal variability of human mesenchymal stem cells cultured under hypoxic conditions. Journal of Cellular and Molecular Medicine 16:72-82.

Wang J, Liao L, Wang S, and Tan J. 2013. Cell therapy with autologous mesenchymal stem cells-how the disease process impacts clinical considerations. Cytotherapy 15:893-904.

Wei X, Yang X, Han Z-p, Qu F-f, Shao L, and Shi Y-f. 2013. Mesenchymal stem cells: a new trend for cell therapy. Acta Pharmacologica Sinica 34:747-754.

Yu JM, Wu X, Gimble JM, Guan X, Freitas MA, and Bunnell BA. 2011. Age-related changes in mesenchymal stem cells derived from rhesus macaque bone marrow. Aging Cell 10:66-79.

Zhou S, Greenberger JS, Epperly MW, Goff JP, Adler C, Leboff MS, and Glowacki J. 2008. Age-related intrinsic changes in human bone-marrow-derived mesenchymal stem cells and their differentiation to osteoblasts. Aging Cell 7:335-343. 


\section{1}

MSC characterization

A) Immunophenotyping of BM-MSC from young and aged donors $(n=3)$. Representative graphs were all positive for CD105, CD90, CD44 and negative for CD19; B) Cumulative population doubling (CPD) of MSC expanded under normal and hypoxic conditions at p15; C) BM-MSC morphology during culture expansion under normal and hypoxic at low passage (P5) and high passage (P15). Arrow indicates differentiated cells that have changed in size and morphology with evidence of cytoplasm spreading $(n=3)$. (Magnification of $x 10$ scale bar $=100 \mu \mathrm{m}) ; \mathrm{D})$ Mesodermal differentiation of young and aged MSCs post exposure to hypoxia. Cells from young and aged MSCs (p15) were cultured in standard medium (control), osteogenic induction medium and adipogenic induction medium respectively. (Magnification of $x 20$ scale bar $=100 \mu \mathrm{m})$; E) Representative reverse-transcription polymerase chain reaction run on $2 \%$ of agarose gel showing expression of aP2 and adiponectin by adipocytes and RUNX2 and osteopontin by osteocytes cells, induced from human bone-marrow mesenchymal stem cells. Control cells without induction medium treatment either did not show any expression or showed lower level of expression of the above markers than the differentiated cells; F) Senescence-associated $\beta$-Gal activity in MSC of normal vs Hypoxic at p15. Results are considered as significantly changed when $* p<0.05$ using one-way ANOVA. 


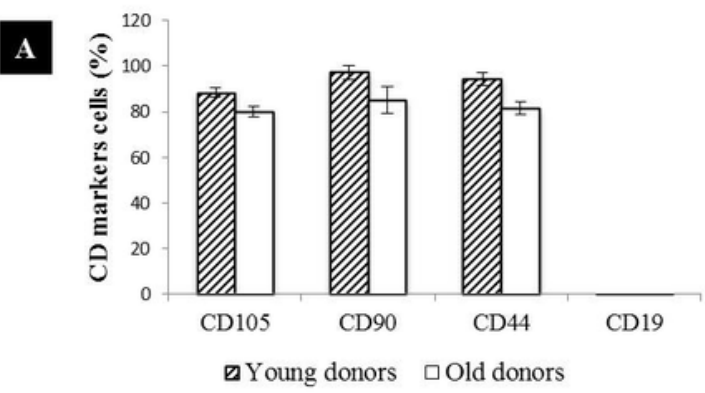

C
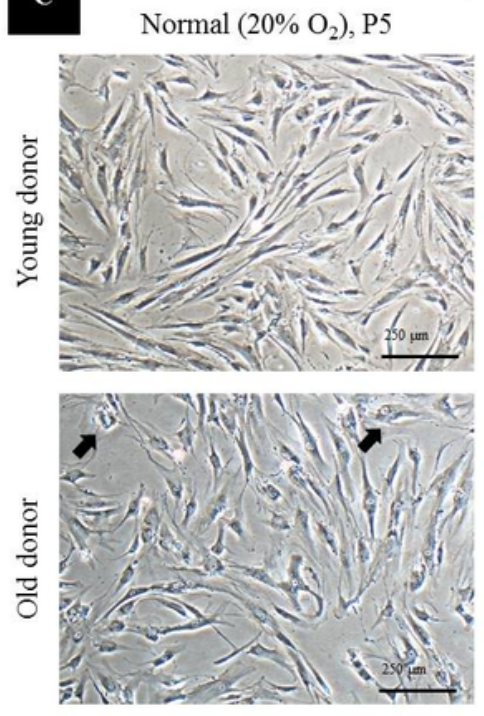

D

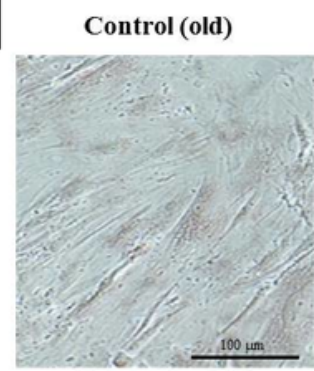

$$
\text { Osteocytes (old) }
$$
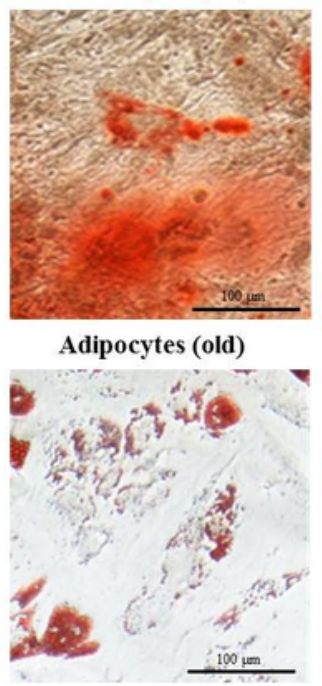

Control (young)

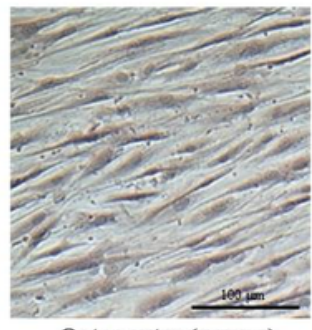

Osteocytes (young)

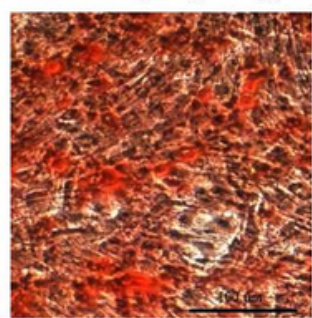

Adipocytes (young)

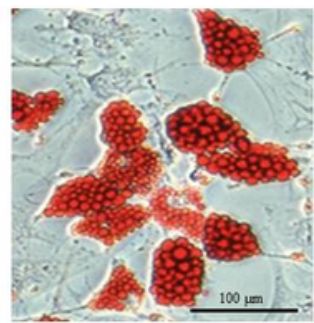

B

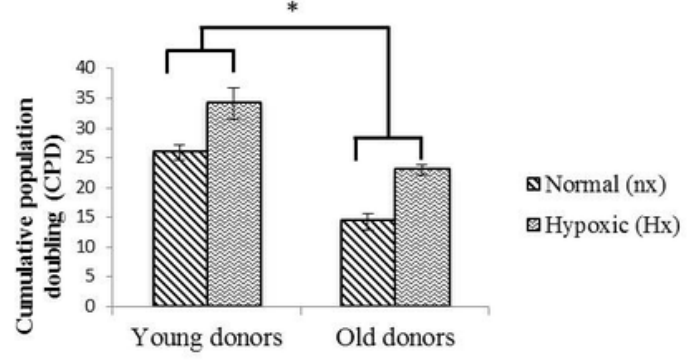

High passage
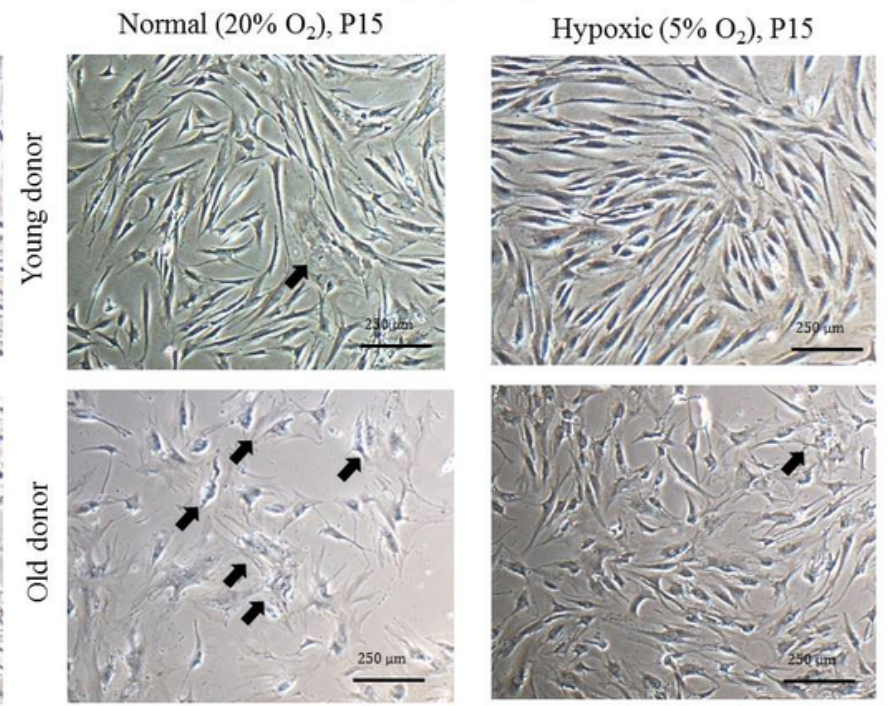

E
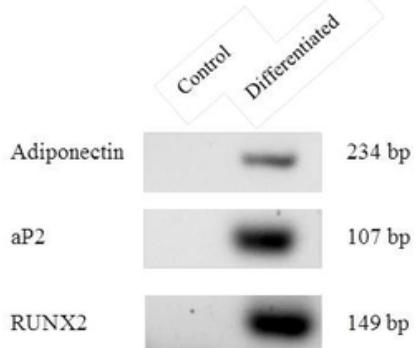

Osteopontin $\quad 778 \mathrm{bp}$

GAPDH

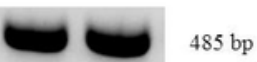

F

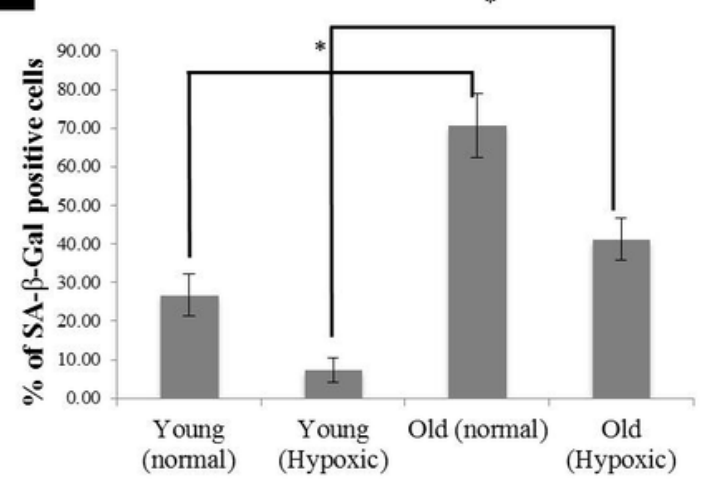


2

\section{NGS Workflow}

Figure 2: Workflow of a miRNA next generation sequencing procedure and data mining.

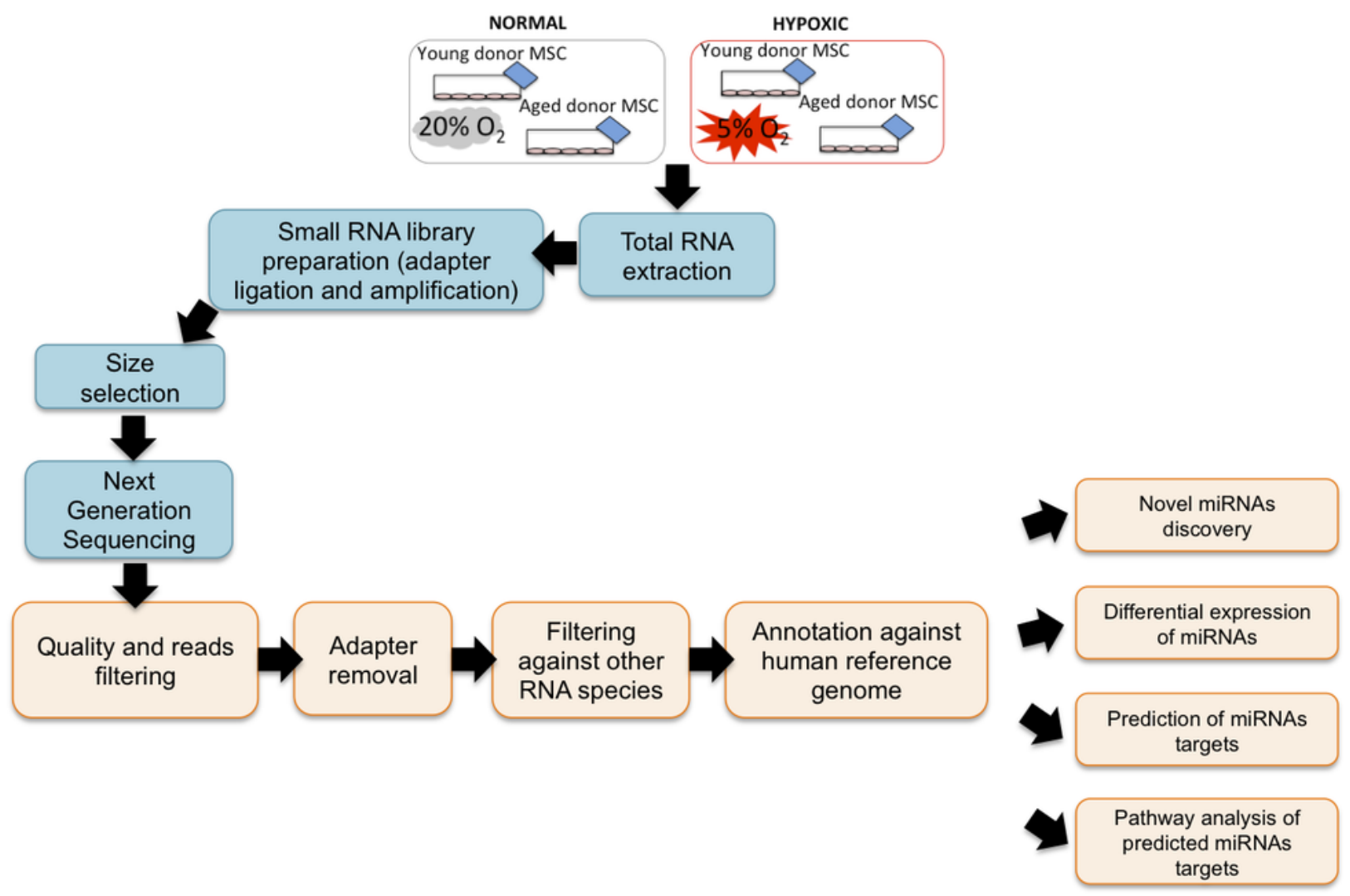


3

Venn-diagram and PCA plot

Figure 3: A) Venn-diagram illustrating groups of miRs that are commonly upregulated and downregulated in young donors, B) Venn-diagram illustrating groups of miRs that are commonly upregulated and downregulated in old donors, C) Principal component analyses indicating the relative distances between the miRNA profiles of different age groups and hypoxic treatment populations.

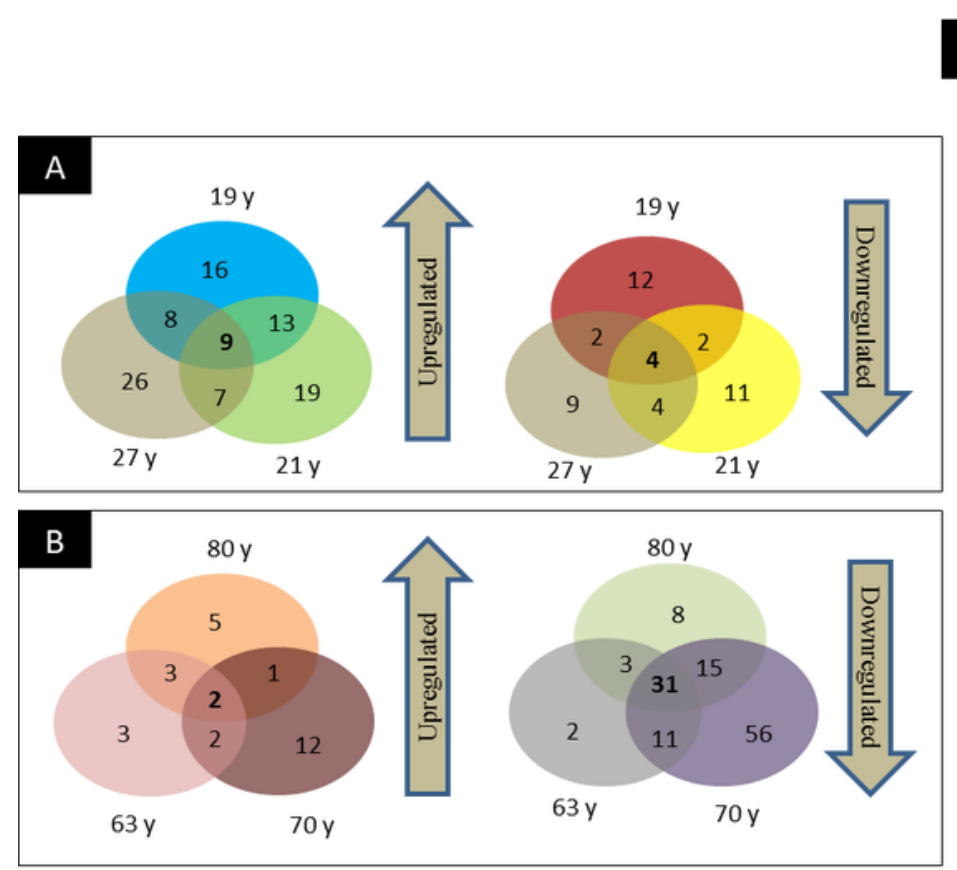

c
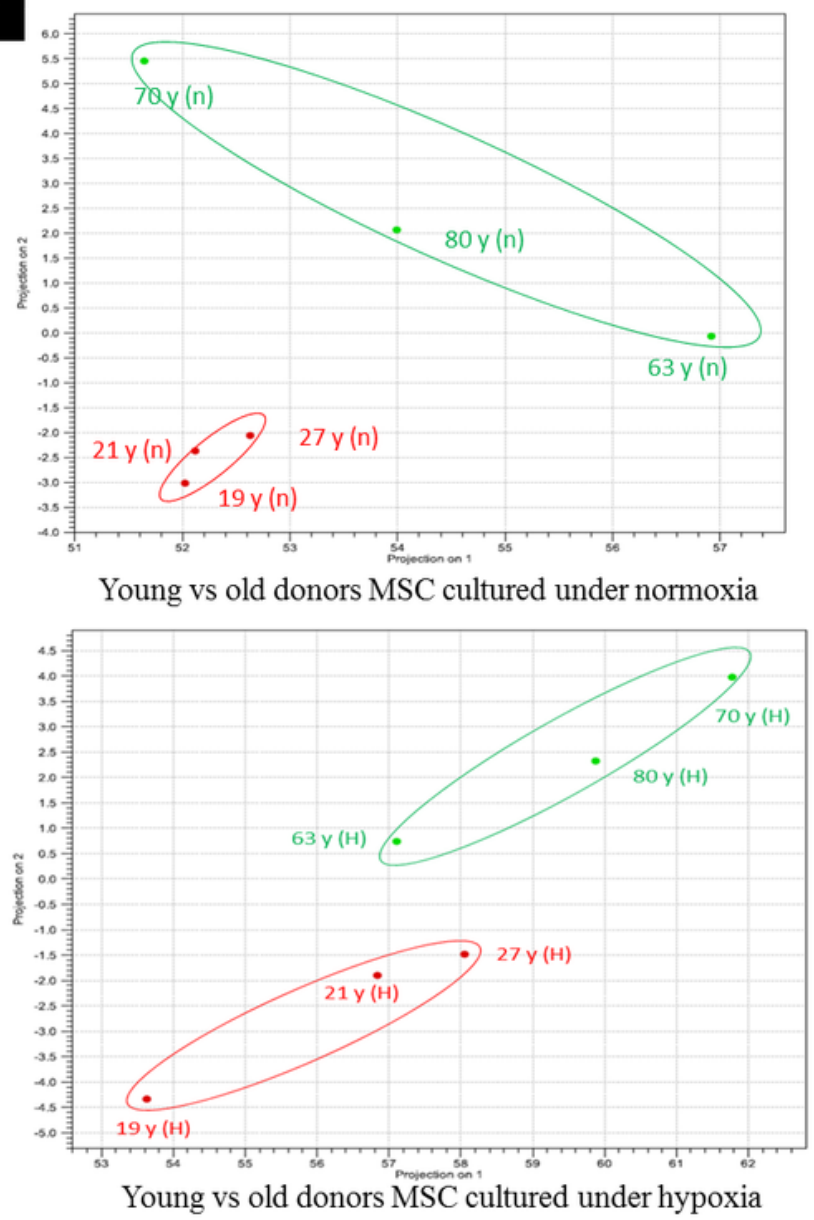
4

qPCR validation and correlation plot

Figure 4: Reproducibility of NGS and comparison of miRNA expression between NGS and qPCR analysis. A) qPCR analysis in MSC of young and old age donors, B) Correlation plot comparing the Fold change values of qPCR with the log2 of the NGS in young donors, C) Correlation plot comparing the Fold change values of qPCR with the log2 of the NGS in old donors. Corresponding R2 values were determined by linear regression analysis.
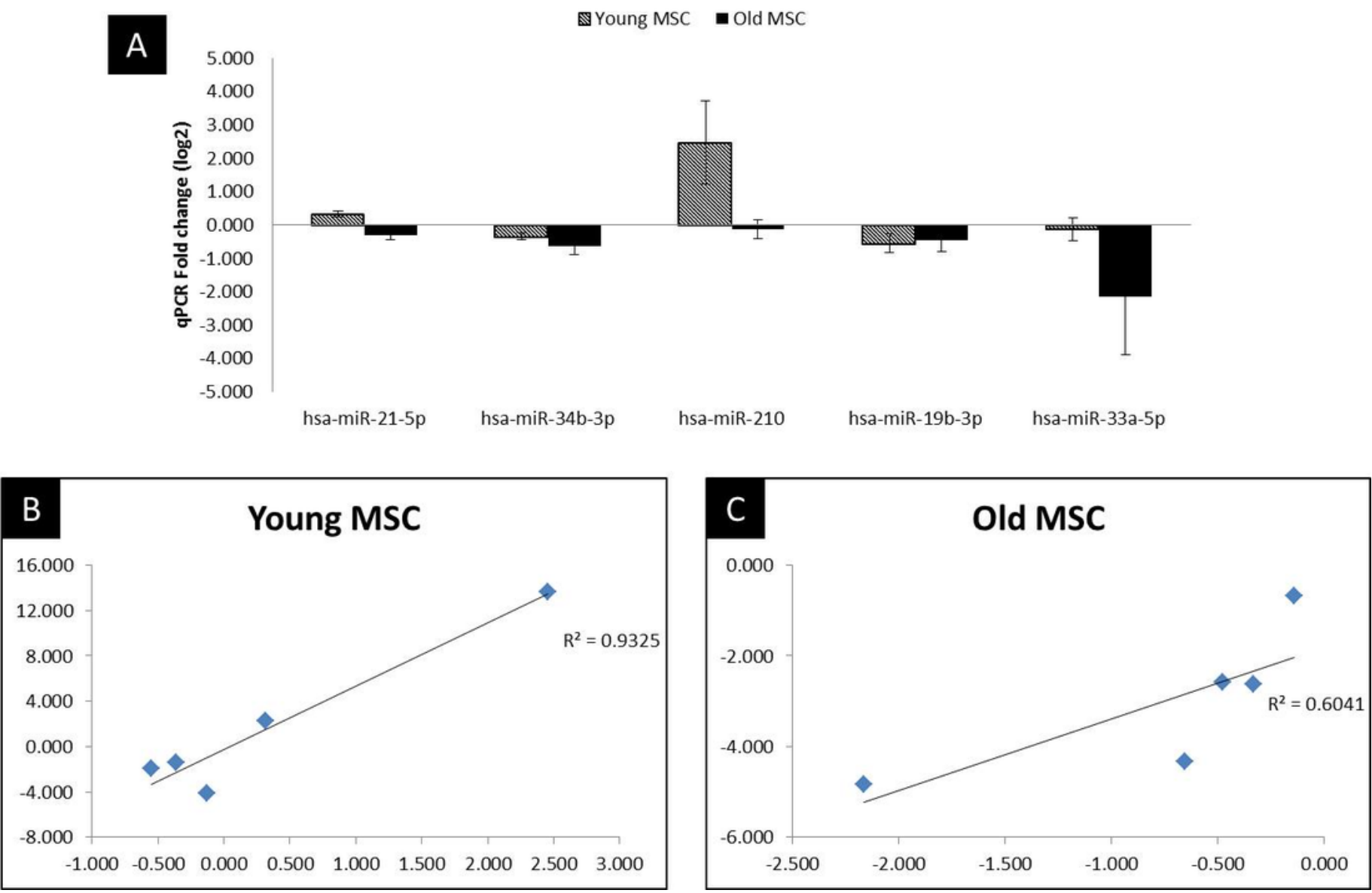


\section{Table 1 (on next page)}

Table 1

The accession number and target sequence of the primers used in the quantitative real-time PCR assay. 
1 Table 1. The accession number and target sequence of the primers used in the quantitative real-

2 time PCR assay.

\begin{tabular}{|l|l|l|}
\hline Name & Accession number & Target Sequence \\
\hline $\begin{array}{l}\text { hsa-miR-200a-3p } \\
\text { (Reference) }\end{array}$ & MIMAT0000682 & UAACACUGUCUGGUAACGAUGU \\
\hline $\begin{array}{l}\text { hsa-miR-122-5p } \\
\text { (Reference) }\end{array}$ & MIMAT0000421 & UGGAGUGUGACAAUGGUGUUUG \\
\hline hsa-miR-34b-3p & MIMAT0004676 & CAAUCACUAACUCCACUGCCAU \\
\hline hsa-miR-210 & MIMAT0000267 & CUGUGCGUGUGACAGCGGCUGA \\
\hline hsa-miR-19b-3p & MIMAT0000074 & UGUGCAAAUCCAUGCAAAACUGA \\
\hline hsa-miR-33a-5p & MIMAT0000091 & GUGCAUUGUAGUUGCAUUGCA \\
\hline hsa-miR-21-5p & MIMAT0000076 & UAGCUUAUCAGACUGAUGUUGA \\
\hline
\end{tabular}

3

4

5

6

7

8

9

10

11

12

13

14

15

16

17 


\section{Table 2 (on next page)}

Table 2

List of differentially expressed miRNAs of MSC from young and aged donors cultured under hypoxic $(\mathrm{Hx})$ culture condition relative to normal $(\mathrm{nx})$ culture condition. 
1 Table 2. List of differentially expressed miRNAs of MSC from young and aged donors cultured

2 under hypoxic (Hx) culture condition relative to normal (nx) culture condition.

3

\begin{tabular}{ccc}
\hline miRNA of young MSC & Fold change $>\mathbf{2}(\mathbf{H x} / \mathbf{n x})$ & p-value \\
\hline mir-210 & 13.64 & 0.0119 \\
mir-423 & 2.58 & 0.0105 \\
mir-1468 & 2.30 & 0.0243 \\
mir-21 & 2.26 & 0.0197 \\
mir-3605 & 2.21 & 0.0061 \\
mir-625 & 2.20 & 0.0709 \\
mir-155 & 2.08 & 0.0071 \\
mir-3065 & 2.07 & 0.0082 \\
mir-138-1 & 2.06 & 0.0034 \\
mir-424 & -2.85 & 0.0073 \\
let-7i & -3.22 & 0.0038 \\
mir-655 & -3.67 & 0.0323 \\
\hline
\end{tabular}

4

5

\begin{tabular}{ccc}
\hline miRNA of aged MSC & Fold change $>\mathbf{2}(\mathbf{H x} / \mathbf{n x})$ & p-value \\
\hline mir-7977 & 2.55 & 0.0350 \\
mir-195 & 2.15 & 0.0061 \\
mir-19b & -2.58 & 0.0280 \\
\hline
\end{tabular}




\begin{tabular}{|c|c|c|}
\hline $\operatorname{mir}-21$ & -2.61 & 0.0089 \\
\hline $\operatorname{mir}-99 a$ & -2.74 & 0.0168 \\
\hline mir-708 & -3.17 & 0.0030 \\
\hline mir-1185-1 & -3.23 & 0.0048 \\
\hline mir-590 & -3.24 & 0.0102 \\
\hline $\operatorname{mir}-455$ & -3.46 & 0.0039 \\
\hline $\operatorname{mir}-374 a$ & -3.53 & 0.0315 \\
\hline $\operatorname{mir}-381$ & -3.53 & 0.0340 \\
\hline mir-126 & -3.87 & 0.0019 \\
\hline mir-196a-2 & -3.99 & 0.0340 \\
\hline mir-136 & -4.03 & 0.0081 \\
\hline $\operatorname{mir}-100$ & -4.29 & 0.0062 \\
\hline mir-34b & -4.33 & 0.0159 \\
\hline $\operatorname{mir}-542$ & -4.35 & 0.0277 \\
\hline mir-376a-1 & -4.35 & 0.0307 \\
\hline mir-1197 & -4.53 & 0.0053 \\
\hline let-7f-2 & -4.69 & 0.0045 \\
\hline $\operatorname{mir}-1228$ & -4.70 & 0.0091 \\
\hline $\operatorname{mir}-2355$ & -4.73 & 0.0143 \\
\hline $\operatorname{mir}-148 b$ & -4.79 & 0.0729 \\
\hline $\operatorname{mir}-33 a$ & -4.84 & 0.0295 \\
\hline $\operatorname{mir}-551 b$ & -4.88 & 0.0013 \\
\hline mir-483 & -6.29 & 0.0061 \\
\hline
\end{tabular}




\begin{tabular}{ccc}
\hline mir-29a & -6.40 & 0.0003 \\
mir-378a & -6.56 & 0.0114 \\
mir-376b & -8.12 & 0.0039 \\
mir-561 & -8.28 & 0.0006 \\
mir-29b-1//mir-29b-2 & -9.30 & 0.0340 \\
mir-193a & -11.88 & 0.0315 \\
mir-627 & -15.00 & 0.0483 \\
\hline
\end{tabular}

$6 \quad(\mathrm{P}<0.05)$ with at least two-fold change 


\section{Table 3(on next page)}

Table 3

The top 5 of highly predicted target genes of differentially expressed miRNAs in young and aged MSCs identified using target prediction program miRDB 
2 Table 3. The top 5 of highly predicted target genes of differentially expressed miRNAs in young

3 and aged MSCs identified using target prediction program miRDB

\begin{tabular}{|c|c|}
\hline Gene symbol (Young & Gene description \\
\hline \multicolumn{2}{|l|}{ MSC) } \\
\hline$\underline{\text { IGF2 }}$ & Insulin-like growth factor 2 (somatomedin A) \\
\hline$\underline{\text { FGFRL1 }}$ & Fibroblast growth factor receptor-like 1 \\
\hline$\underline{\text { PTPN21 }}$ & Protein tyrosine phosphatase, non-receptor type 21 \\
\hline$\underline{\mathrm{ISCU}}$ & Iron-sulfur cluster scaffold homolog (E. coli) \\
\hline$\underline{\text { SLC25A26 }}$ & Solute carrier family 25, member 26 \\
\hline Gene symbol (Aged MSC) & Gene description \\
\hline FGF2 & Fibroblast growth factor 2 (basic) \\
\hline MTMR3 & Myotubularin related protein 3 \\
\hline CASK & $\begin{array}{l}\text { Calcium/calmodulin-dependent serine protein kinase } \\
\text { (MAGUK family) }\end{array}$ \\
\hline WEE1 & WEE1 homolog (S. pombe) \\
\hline$\underline{\text { CCNE1 }}$ & Cyclin E1 \\
\hline
\end{tabular}

4

5

6

7

8

9

10 


\section{Table 4 (on next page)}

Table 4

The top 10 of highly enriched gene ontology (GO) terms of biological processes in predicted targets miRNAs (fold change $>2$ ) of MSC from young and aged donors cultured under hypoxic $(\mathrm{Hx})$ culture condition relative to normal $(\mathrm{nx})$ culture condition. A) Top 10 of highly enriched GO (biological processes) in MSC from young donors, B) Top 10 of highly enriched GO (biological processes) in MSC from aged donors 
2 Table 4. The top 10 of highly enriched gene ontology (GO) terms of biological processes in

3 predicted targets miRNAs (fold change $>2$ ) of MSC from young and aged donors cultured under

4 hypoxic $(\mathrm{Hx})$ culture condition relative to normal $(\mathrm{nx})$ culture condition.

6 A) Top 10 of highly enriched GO (biological processes) in MSC from young donor

\begin{tabular}{|c|c|c|c|c|}
\hline Function & p-value & Count & $\%$ & $\begin{array}{l}\text { Fold } \\
\text { enrichment }\end{array}$ \\
\hline $\begin{array}{l}\text { Regulation of transcription from RNA } \\
\text { polymerase II promoter in response to } \\
\text { oxidative stress GO:0043619 }\end{array}$ & $\begin{array}{l}3.70 \mathrm{E}- \\
02\end{array}$ & 3 & 0.2 & 9 \\
\hline Polyol transport GO:0015791 & $\begin{array}{l}9.50 \mathrm{E}- \\
03\end{array}$ & 4 & 0.3 & 8 \\
\hline Synaptic vesicle maturation GO:0016188 & $\begin{array}{c}5.80 \mathrm{E}- \\
02\end{array}$ & 3 & 0.2 & 7.2 \\
\hline Protein palmitoylation GO:0018345 & $\begin{array}{l}5.80 \mathrm{E}- \\
02\end{array}$ & 3 & 0.2 & 7.2 \\
\hline $\begin{array}{l}\text { Healing during inflammatory response } \\
\text { GO:0002246 }\end{array}$ & $\begin{array}{c}5.80 \mathrm{E}- \\
02\end{array}$ & 3 & 0.2 & 7.2 \\
\hline $\begin{array}{l}\text { Regulation of transcription from RNA } \\
\text { polymerase II promoter in response to } \\
\text { stress GO:0043618 }\end{array}$ & $\begin{array}{c}5.80 \mathrm{E}- \\
02\end{array}$ & 3 & 0.2 & 7.2 \\
\hline Nuclear pore organization GO:0006999 & $5.80 \mathrm{E}-$ & 3 & 0.2 & 7.2 \\
\hline
\end{tabular}




\begin{tabular}{lcccc}
\hline Regulation of transcription in response to & 02 & & & \\
\hline stress GO:0043620 & $5.80 \mathrm{E}-$ & 3 & 0.2 & 7.2 \\
Definitive hemopoiesis GO:0060216 & 02 & & & 6.9 \\
\hline Embryonic camera-type eye & 02 & 4 & 0.3 & 6 \\
$\underline{\text { morphogenesis GO:0048596 }}$ & $2.30 \mathrm{E}-$ & & & \\
\hline
\end{tabular}

7

B) Top 10 of highly enriched GO (biological processes) in MSC from aged donor

\begin{tabular}{|c|c|c|c|c|}
\hline Function & p-value & Count & $\%$ & $\begin{array}{l}\text { Fold } \\
\text { enrichment }\end{array}$ \\
\hline $\begin{array}{l}\text { Negative regulation of epithelial to } \\
\text { mesenchymal transition GO:0010719 }\end{array}$ & $\begin{array}{c}4.00 \mathrm{E}- \\
02\end{array}$ & 2 & 0.6 & 49.2 \\
\hline $\begin{array}{l}\text { Voluntary musculoskeletal movement } \\
\text { GO:0050882 }\end{array}$ & $\begin{array}{l}4.00 \mathrm{E}- \\
02\end{array}$ & 2 & 0.6 & 49.2 \\
\hline $\begin{array}{l}\text { Negative regulation of cell morphogenesis } \\
\text { involved in differentiation GO:0010771 }\end{array}$ & $\begin{array}{c}6.00 \mathrm{E}- \\
02\end{array}$ & 2 & 0.6 & 32.8 \\
\hline Epithelial cell maturation GO:0002070 & $\begin{array}{l}9.70 \mathrm{E}- \\
02\end{array}$ & 2 & 0.6 & 19.7 \\
\hline $\begin{array}{l}\text { Regulation of calcium ion-dependent } \\
\text { exocytosis GO:0017158 }\end{array}$ & $\begin{array}{l}1.30 \mathrm{E}- \\
02\end{array}$ & 3 & 0.8 & 16.4 \\
\hline $\begin{array}{l}\text { Vesicle transport along microtubule } \\
\text { GO:0047496 }\end{array}$ & $\begin{array}{l}1.30 \mathrm{E}- \\
02\end{array}$ & 3 & 0.8 & 16.4 \\
\hline
\end{tabular}




\begin{tabular}{lcccc}
\hline$\underline{\text { Regulation of epithelial to mesenchymal }}$ & $1.30 \mathrm{E}-$ & 3 & 0.8 & 16.4 \\
$\underline{\text { transition GO:0010717 }}$ & 02 & & & \\
$\underline{\text { Protein ubiquitination during ubiquitin- }}$ & $4.50 \mathrm{E}-$ & & & 11.6 \\
$\underline{\text { dependent protein catabolic process }}$ & 03 & 4 & 1.1 & 10.5 \\
GO:0042787 & $3.20 \mathrm{E}-$ & 3 & 0.8 & \\
Cerebral cortex cell migration & 02 & & & \\
GO:0021795 & $3.60 \mathrm{E}-$ & 3 & 0.8 & \\
\hline$\underline{\text { Bone resorption GO:0045453 }}$ & 02 & & & \\
\hline
\end{tabular}

9

10 


\section{Table 5 (on next page)}

Table 5

KEGG pathways enrichment of miRNA target predicted genes (fold change $>2$ ) of MSC from young and aged donors cultured under hypoxic $(\mathrm{Hx})$ culture condition relative to normal $(\mathrm{nx})$ culture condition. A) KEGG pathways enrichment of miRNA target predicted genes of young MSC, B) KEGG pathways enrichment of miRNA target predicted genes of aged MSC. 
1 Table 5. KEGG pathways enrichment of miRNA target predicted genes (fold change $>2$ ) of

2 MSC from young and aged donors cultured under hypoxic (Hx) culture condition relative to

3 normal (nx) culture condition.

4 A) KEGG pathways enrichment of miRNA target predicted genes of young MSC

\begin{tabular}{|c|c|c|c|c|c|c|}
\hline Pathways & Count & $\%$ & P-Value & $\begin{array}{c}\text { Fold } \\
\text { Enrichment }\end{array}$ & Benjamini & FDR \\
\hline GnRH signaling pathway & 17 & 1.1 & $\begin{array}{c}1.30 \mathrm{E}- \\
03\end{array}$ & 2.4 & $2.00 \mathrm{E}-01$ & $1.50 \mathrm{E}+00$ \\
\hline Melanogenesis & 16 & 1 & $\begin{array}{l}3.80 \mathrm{E}- \\
03\end{array}$ & 2.3 & $2.00 \mathrm{E}-01$ & $4.50 \mathrm{E}+00$ \\
\hline $\begin{array}{l}\text { Vascular smooth muscle } \\
\text { contraction }\end{array}$ & 16 & 1 & $\begin{array}{l}1.20 \mathrm{E}- \\
02\end{array}$ & 2 & $4.00 \mathrm{E}-01$ & $1.40 \mathrm{E}+01$ \\
\hline Type II diabetes mellitus & 9 & 0.6 & $\begin{array}{l}1.60 \mathrm{E}- \\
02\end{array}$ & 2.7 & $4.30 \mathrm{E}-01$ & $1.80 \mathrm{E}+01$ \\
\hline Gap junction & 13 & 0.9 & $\begin{array}{l}2.20 \mathrm{E}- \\
02\end{array}$ & 2.1 & 4.20E-01 & $2.40 \mathrm{E}+01$ \\
\hline $\begin{array}{l}\text { MAPK signaling } \\
\text { pathway }\end{array}$ & 29 & 1.9 & $\begin{array}{l}2.20 \mathrm{E}- \\
02\end{array}$ & 1.5 & $4.70 \mathrm{E}-01$ & $2.30 \mathrm{E}+01$ \\
\hline Wnt signaling pathway & 18 & 1.2 & $\begin{array}{c}3.70 \mathrm{E}- \\
02\end{array}$ & 1.7 & $5.20 \mathrm{E}-01$ & $3.70 \mathrm{E}+01$ \\
\hline ErbB signaling pathway & 12 & 0.8 & $\begin{array}{l}\text { 4.20E- } \\
02\end{array}$ & 1.9 & $5.20 \mathrm{E}-01$ & $4.10 \mathrm{E}+01$ \\
\hline Adherens junction & 11 & 0.7 & 4.40E- & 2 & $5.00 \mathrm{E}-01$ & $4.20 \mathrm{E}+01$ \\
\hline
\end{tabular}




\begin{tabular}{lcccccc}
\hline Long-term potentiation & 10 & 0.7 & $4.90 \mathrm{E}-$ & 2.1 & $5.10 \mathrm{E}-01$ & $4.60 \mathrm{E}+01$ \\
& & & 02 & & \\
& & & & & & \\
\end{tabular}

6 B) KEGG pathways enrichment of miRNA target predicted genes of aged MSC

\begin{tabular}{|c|c|c|c|c|c|c|}
\hline Pathways & Count & $\%$ & P-Value & $\begin{array}{c}\text { Fold } \\
\text { Enrichm } \\
\text { ent }\end{array}$ & $\begin{array}{l}\text { Benjam } \\
\text { ini }\end{array}$ & FDR \\
\hline Insulin signaling pathway & 10 & 2.8 & $\begin{array}{c}1.70 \mathrm{E}- \\
03\end{array}$ & 3.6 & $\begin{array}{c}1.90 \mathrm{E}- \\
01\end{array}$ & $\begin{array}{c}2.00 \mathrm{E}+0 \\
0\end{array}$ \\
\hline Wnt signaling pathway & 9 & 2.5 & $\begin{array}{l}1.20 \mathrm{E}- \\
02\end{array}$ & 2.9 & $\begin{array}{l}3.10 \mathrm{E}- \\
01\end{array}$ & $\begin{array}{c}1.30 \mathrm{E}+0 \\
1\end{array}$ \\
\hline p53 signaling pathway & 6 & 1.7 & $\begin{array}{l}1.30 \mathrm{E}- \\
02\end{array}$ & 4.2 & $\begin{array}{l}2.60 \mathrm{E}- \\
01\end{array}$ & $\begin{array}{c}1.40 \mathrm{E}+0 \\
1\end{array}$ \\
\hline $\begin{array}{l}\text { B cell receptor signaling } \\
\text { pathway }\end{array}$ & 6 & 1.7 & $\begin{array}{l}1.90 \mathrm{E}- \\
02\end{array}$ & 3.8 & $\begin{array}{l}3.10 \mathrm{E}- \\
01\end{array}$ & $\begin{array}{c}2.00 \mathrm{E}+0 \\
1\end{array}$ \\
\hline Cell cycle & 7 & 2 & $\begin{array}{l}\text { 4.40E- } \\
02\end{array}$ & 2.7 & $\begin{array}{c}3.20 \mathrm{E}- \\
01\end{array}$ & $\begin{array}{c}4.00 \mathrm{E}+0 \\
1\end{array}$ \\
\hline MAPK signaling pathway & 11 & 3.1 & $\begin{array}{l}\text { 4.80E- } \\
02\end{array}$ & 2 & $\begin{array}{c}3.20 \mathrm{E}- \\
01\end{array}$ & $\begin{array}{c}4.30 \mathrm{E}+0 \\
1\end{array}$ \\
\hline $\begin{array}{l}\text { Calcium signaling } \\
\text { pathway }\end{array}$ & 8 & 2.2 & $\begin{array}{l}7.10 \mathrm{E}- \\
02\end{array}$ & 2.2 & $\begin{array}{c}3.80 \mathrm{E}- \\
01\end{array}$ & $\begin{array}{c}5.70 \mathrm{E}+0 \\
1\end{array}$ \\
\hline Type II diabetes mellitus & 4 & 1.1 & 7.20E- & 4.1 & $3.60 \mathrm{E}-$ & $5.80 \mathrm{E}+0$ \\
\hline
\end{tabular}




$$
02
$$

\begin{tabular}{lcccccc} 
mTOR signaling pathway & 4 & 1.1 & $9.10 \mathrm{E}-$ & 3.7 & $4.20 \mathrm{E}-$ & $6.70 \mathrm{E}+0$ \\
& & 02 & 01 & 1 \\
\hline
\end{tabular}

